\title{
A CONSTRUÇÃO DA IDENTIDADE DOS PROFESSORES DE BEBÊS COMO INSTRUMENTO DE PROFISSIONALIDADE DOCENTE NA EDUCAÇÃO INFANTIL: UMA REVISÃO
}

\author{
THE CONSTRUCTION OF THE IDENTITY OF BABY TEACHERS AS AN INSTRUMENT OF \\ PROFESSIONALITY \\ TEACHER IN CHILDHOOD EDUCATION: A REVIEW
}

\author{
Gisleine Cristina Silva ${ }^{1}$ \\ Maria de Jesus Cano Mirandar ${ }^{2}$
}

"Mas na profissão, além de amar tem de saber. E o saber leva tempo pra crescer."

\section{(Rubem Alves)}

RESUMO: As contínuas e rápidas transformações da sociedade contemporânea trazem consigo a imposição da construção da identidade do professor de bebês, a fim de desenvolver sua profissionalidade, assim como, um novo perfil docente. Diante disso, o presente estudo teve como objetivo apresentar uma revisão de artigos, a fim de discutir como a construção da identidade dos professores de bebês é um fator imprescindível para a profissionalização docente na educação infantil. Trata-se de uma pesquisa de revisão integrativa da literatura cujos procedimentos metodológicos envolveram levantamento da literatura em fevereiro de 2021, nas bases de dados Periódicos CAPES e Google Acadêmico o que permitiu a identificação de 15 artigos que se adequaram aos critérios de elegibilidade, leitura dos artigos e escrita do texto. Como resultado pode-se verificar que a construção da identidade do professor de bebê é fundamental para que esse profissional tenha o seu trabalho pedagógico reconhecido e valorizado e com isso ocorra a superação da visão assistencialista do atendimento de bebês na educação infantil. Conclui-se que é essencial garantir ao professor do berçário o acesso a cursos de formação continuada de longa duração e de qualidade capazes de contribuírem com o desenvolvimento dos saberes específicos e necessários ao trabalho com bebês, pois possibilita a criação de um novo perfil profissional, a construção da sua identidade, a ressignificação $d a$ prática $e$ consequentemente a profissionalidade docente.

\footnotetext{
I Possui graduação em Pedagogia pela Universidade Estadual de Maringá (2014), especialização em Educação Especial com ênfase em TGD pelo Grupo Rhema de Educação (2015) e especialização em Psicopedagogia Clínica e Institucional pela Universidade Estadual de Maringá (2017).

${ }^{2}$ Possui graduação em Letras Anglo Portuguesa pela Universidade Estadual de Maringá (1970), graduação em Pedagogia pela Universidade Estadual de Maringá (1979), mestrado em Educação pela Universidade Estadual de Maringá (200I) e doutorado em Educação Escolar pela Universidade Estadual Paulista Júlio Mesquita Filho (2011).
} 
Palavras-chave: Construção da identidade docente. Professores de bebês. Educação infantil. Profissionalização docente.

ABSTRACT: The continuous and fast transformations of contemporary society bring with them the imposition of the construction of the identity of the baby teacher, to develop his professionalism, as well as a new teaching profile. Given this situation, the work aimed to present a review of papers, to discuss how the construction of the identity of the teachers of babies is an essential factor for the professionalization of these educators in early childhood education. This is an integrative literature review research whose methodological procedures involved a literature survey in February 2021, in the CAPES and Google Scholar databases, allowing the identification of 15 articles that met the eligibility criteria, reading the articles and writing the text. As a result, it can be seen that the construction of the baby teacher's identity is fundamental for this professional to have his/her pedagogical work recognized and valued, overcoming the existentialist view of baby care in early childhood education. The present research concludes that is essential to guarantee the nursery teacher access to long-term and quality continuing education courses, capable of contributing to the development of the specific knowledge necessary for working with babies. Because, it allows the creation of a new professional profile, the construction of its identity, the re-signification of practice, and, consequently, the teaching professionalism.

Keywords: Construction of teaching identity. Baby teachers. Child education. Teacher professionalization.

\section{INTRODUÇÃO}

Vivemos tempos líquidos na contemporaneidade. Ou seja, passamos por muitas transformações em ritmo intenso e acelerado em todas as esferas da sociedade o que têm impactado significativamente a vida das pessoas, suas relações, o mundo do trabalho e consequentemente, a escola (BAUMAN, 200I).

Consequentemente, as contínuas e rápidas transformações da sociedade contemporânea trazem consigo a imposição da construção da identidade do professor de bebês, a fim de desenvolver sua profissionalidade, assim como, um novo perfil docente.

Desse modo, a identidade do ponto de vista etimológico significa: Primeiro: Qualidade de idêntico. Segundo: Os caracteres próprios e exclusivos duma pessoa como: nome, idade, estado, profissão, sexo, etc. (FERREIRA, 2oı). E, do ponto de vista sociológico diz respeito ao conjunto de características pelas quais um indivíduo ou grupo pode ser reconhecido. (GOMES, 2018).

Já, do ponto de vista antropológico pode-se dizer que há uma semelhança com a visão sociológica na medida em que considera que a identidade tem ao mesmo tempo uma dimensão individual e uma dimensão coletiva. No que toca a individualidade, a identidade refere-se à percepção que o sujeito tem de si mesmo e na coletividade confunde-se com os papéis que o sujeito desempenha nos diferentes grupos sociais dos quais pertence (GOMES, 2018). 
Assim sendo, para Onofre, Tomazzetti e Martins (2017) a identidade do profissional docente segundo Nóvoa (1992) e Tardif (2002) diz respeito a um processo que ocorre ao longo da carreira e da trajetória de vida do sujeito.

Logo, a identidade dos professores de bebês é construída por meio de diferentes fontes de saberes e marcas pessoais e profissionais caracterizando um repertório complexo de histórias e conhecimento (SILVA, SOUZA E BRAGA, 2020).

Nesse sentido, é de máxima importância repensar-se a formação contínua dos docentes partindo da diversidade de saberes fundamentais à sua pratica docente e ressignificando e valorizando os saberes já construídos por meio de uma postura reflexiva, investigativa e crítica.

Sabe-se que o professor da educação infantil tem uma grande importância na vida das crianças pequenas assim consequentemente sua formação é um ponto chave no contexto educacional, pois essa etapa da educação impõe a necessidade de se ter profissionais capacitados e comprometidos (CAMARGO, BIAGINI e CORREAA, 2018) com o desenvolvimento global das crianças e o ensino humanizado a partir de práticas pedagógicas lúdicas, emancipatórias, humanizadas e potencializadoras das funções psicológicas superiores (SAITO e OLIVEIRA, 2018).

Em virtude disso, o estudo foi movido por inquietações que despertaram o interesse em aprofundar o assunto no que toca a construção da identidade do professor de bebês, bem como, o desenvolvimento da profissionalidade docente. Assim sendo, o questionamento que norteou tal estudo foi: Em que medida esse estudo pode contribuir com a construção da identidade e com a profissionalidade dos docentes de bebês no contexto da educação infantil?

E, justifica-se devido a urgência da construção da identidade dos professores de bebês, uma vez que, que a identidade docente pode ser um instrumento de profissionalidade por meio do desenvolvimento de um novo perfil docente, a partir de uma formação continuada específica para o trabalho com bebês e da superação do caráter assistencialista do atendimento a crianças dessa faixa etária que ainda hoje persiste.

Nesse sentido, o presente artigo trata-se de um estudo sistemático cujo objetivo foi apresentar uma revisão de artigos, a fim de discutir como a construção da identidade dos professores de bebês é um fator imprescindível para a profissionalização docente na educação infantil.

O presente estudo foi organizado em três partes articuladas entre si, sendo que na introdução discute-se a temática no geral e é apresentado o objetivo da pesquisa, a problematização e a justificativa.

$\mathrm{Na}$ segunda parte, apresenta-se o desenvolvimento do estudo que foi subdividido em: metodologia, resultados, discussão. E, na terceira parte refere-se às considerações finais na qual busca-se discutir, apresentar o ponto de vista e fazer uma reflexão diante da temática em questão.

\section{Materiais e métodos}

Foi feito um levantamento da literatura em fevereiro de 2020, nas bases de dados Periódicos CAPES e Google Acadêmico. Os descritores utilizados foram os seguintes: 
"Construção" AND “Identidade" AND "Docentes de bebês" AND "Profissionalização docente" AND "Educação Infantil" e "Construction" AND "Identity" AND "Baby teachers" AND "Teacher professionalization" AND "Early Childhood Education" em todas as bases de dados. Foram selecionados 15 artigos sendo incluídos segundo os critérios de elegibilidade conforme a Figura I. Os critérios de inclusão foram: artigos nos idiomas inglês e português, nos últimos cinco anos, envolvendo a construção da identidade dos docentes de bebês como um instrumento de profissionalização docente na Educação Infantil. Os critérios de exclusão foram artigos de revisão de literatura.
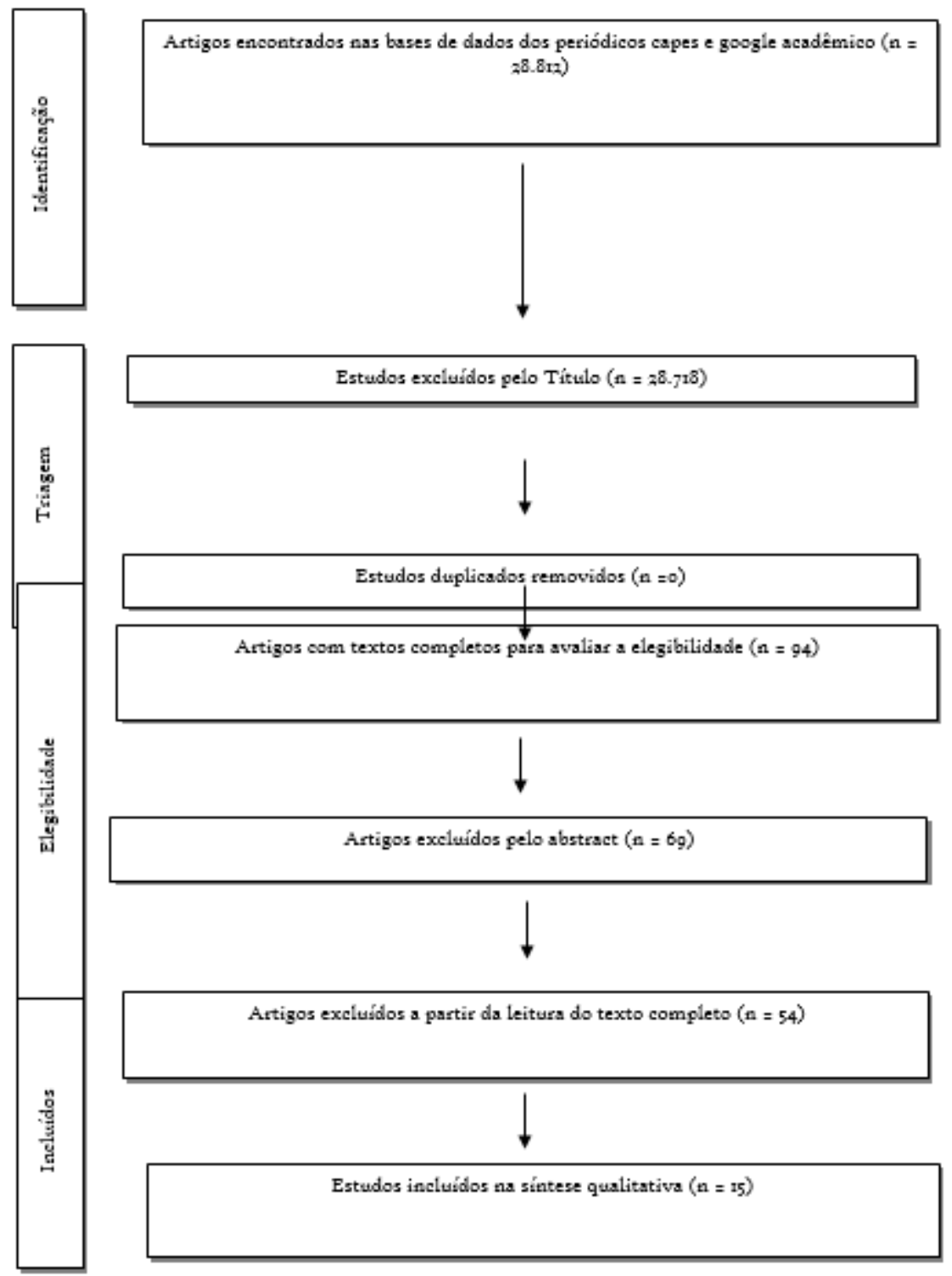

$$
3 \text { RESUlTADOS }
$$

Os resultados do presente estudo encontram-se na Tabela 1. 
Revista Ibero- Americana de Humanidades, Ciências e Educação- REASE $\quad$ open access $^{\text {a }}$

Tabela 1 - Demonstrativo dos artigos que integram a Revisão Integrativa

\begin{tabular}{|c|c|c|c|c|c|c|c|}
\hline$\# \mathbf{N}$ & Data & Título & Autores & & eriódico & Objetivos & Resultados \\
\hline 1 & 2020 & $\begin{array}{l}\text { Ser e se sentir professor na } \\
\text { educação infantil: o que } \\
\text { falam os docentes }\end{array}$ & $\begin{array}{l}\text { Alessandro Messias } \\
\text { Moreira, Celso Augusto } \\
\text { dos Santos Gomes, Renan } \\
\text { Antônio da Silva, Stefano } \\
\text { Barra Gazolla, Felipe } \\
\text { Flausino de Oliveira, Luiz } \\
\text { Carlos Vieira Guedes. }\end{array}$ & $\begin{array}{ll}\text { Revista } & \mathrm{Hu} \\
\text { Inovação } & \end{array}$ & Humanidades $\mathrm{e}$ & $\begin{array}{l}\text { Conhecer as peculiaridades da } \\
\text { prática, como esses docentes se } \\
\text { reconhecem profissionalmente, quais } \\
\text { são seus discursos e como todos } \\
\text { esses elementos corroboram na } \\
\text { construção da sua identidade } \\
\text { profissional. }\end{array}$ & $\begin{array}{l}\text { Evidenciou-se que a constituição identitária } \\
\text { do "ser professora" caracteriza-se na } \\
\text { contradição entre aquilo que é peculiar ao } \\
\text { sujeito e aquilo que é intrínseco a sua classe } \\
\text { profissional. Essa identidade, que é única, ao } \\
\text { mesmo tempo em que se dá no coletivo da } \\
\text { profissão, traz ao sujeito possibilidades de } \\
\text { defesa e de garantia estrutural para vivência } \\
\text { em sociedade. }\end{array}$ \\
\hline 2 & 2020 & $\begin{array}{l}\text { Formação e prática de } \\
\text { professores de bebês: } \\
\text { entrelaços com os cursos de } \\
\text { docência na educação infantil } \\
\text { na universidade federal do } \\
\text { Pará }\end{array}$ & $\begin{array}{l}\text { Solange Mochiutti, } \\
\text { Marileia Pereira Trindade }\end{array}$ & $\begin{array}{l}\text { Brazilian } \\
\text { Development }\end{array}$ & tournal & $\begin{array}{l}\text { Analisar a experiência formativa no } \\
\text { Curso de Especialização em } \\
\text { Docência em Educação Infantil, } \\
\text { ocorrida na Universidade Federal do } \\
\text { Pará e relação dessa formação com a } \\
\text { prática de professoras com bebês. }\end{array}$ & $\begin{array}{l}\text { Os resultados apontam que as professoras } \\
\text { tinham necessidades de formação acerca das } \\
\text { especificidades do bebê e do trabalho docente } \\
\text { destinado a eles. }\end{array}$ \\
\hline 3 & 2020 & $\begin{array}{l}\text { Reflexões sobre a construção } \\
\text { da identidade profissional de } \\
\text { uma docente da educação } \\
\text { infantil }\end{array}$ & $\begin{array}{l}\text { Jéssica Francine } \text { Ferreira } \\
\text { da Silva, Ana Paula } \\
\text { Gestoso de Souza, } \\
\text { Andréia Barboza Braga. }\end{array}$ & Revista Exitus & & $\begin{array}{l}\text { Analisar e compreender as } \\
\text { experiências relatadas no memorial } \\
\text { de formação e, desse modo, } \\
\text { procuramos identificar e observar } \\
\text { indícios da construção de sua } \\
\text { identidade profissional. }\end{array}$ & $\begin{array}{l}\text { O estudo revelou o quanto a trajetória de vida } \\
\text { e de formação influenciam fortemente na } \\
\text { construção da identidade docente. Identidade } \\
\text { essa que não é estática e não se encerra em } \\
\text { determinados momentos da vida ou da } \\
\text { carreira, mas é permanente e contínua. }\end{array}$ \\
\hline 4 & 2020 & $\begin{array}{l}\text { A solidão profissional de } \\
\text { professoras de bebês }\end{array}$ & $\begin{array}{l}\text { Marlene Oliveira dos } \\
\text { Santos. }\end{array}$ & $\begin{array}{l}\text { Revista I } \\
\text { Artes de Educ }\end{array}$ & $\begin{array}{l}\text { Interinstitucional } \\
\text { acar }\end{array}$ & $\begin{array}{l}\text { Discutir a solidão profissional vivida } \\
\text { por professoras de bebês, a } \\
\text { partir dos resultados de uma pesquisa } \\
\text { sobre currículos praticados com } \\
\text { bebês. }\end{array}$ & $\begin{array}{l}\text { Os resultados da pesquisa mostraram que a } \\
\text { ação pedagógica com os bebês se movimenta } \\
\text { em diferentes direções e se fundamenta em } \\
\text { distintos campos de conhecimento. }\end{array}$ \\
\hline
\end{tabular}

576 
Revista Ibero- Americana de Humanidades, Ciências e Educação- REASE $\quad{ }_{\text {open }}^{\text {access }}$

\#N

Data

Título
Autores

Periódico

Objetivos

Resultados docentes em berçários

2019 Profissão

considerações identidade docente
Professor: Claudiane Pinto Dias de CONEDU a Jesus, Maria Alice Melo.

(2)
de Tecer relações entre identidade, As análises indicaram que, embora a prática cultura, gênero e poder, aproximando nos berçários envolvesse múltiplos saberes e a área dos estudos culturais ao campo- culturas, produzia-se nos discursos dos

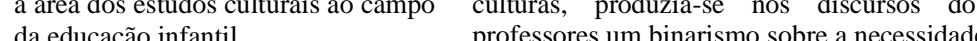 professores un binarismo sobre a necessidade de cuidar e educar en que cuidar associava-se às práticas do passado e educar aproximava- se ao seu novo papel profissional,
representando estratégias identitárias para valorizar a docência com bebês.
Compreender os elementos Constatamos que a presença feminina é constituintes do processo de significativa na instituição analisada, o corpo construção da identidade profissional docente é formado por pessoas da dos professores que atuam nas comunidade havendo similaridades entre a escolas comunitárias de um identidade do professor e os demais membros município de São Luís-MA. da comunidade, tendo em vista que os interesses são comuns, concluímos ainda que fatores como salário, valorização da categoria e condições de trabalho não são aspectos relevantes para os profissionais da escola pesquisada.


Revista Ibero- Americana de Humanidades, Ciências e Educação- REASE ${ }_{\text {open }}^{\text {○ }}{ }^{\text {access }}$

\begin{tabular}{|c|c|c|c|c|c|c|}
\hline$\# \mathbf{N}$ & Data & Título & Autores & Periódico & Objetivos & Resultados \\
\hline 7 & 2018 & $\begin{array}{lrr}\text { Ser professor/a } & \text { iniciante } \\
\text { reflexões sobre } & \text { sua } \\
\text { identidade e especificidades }\end{array}$ & $\begin{array}{l}\text { Janaina Nogueira Maia } \\
\text { Carvalho }\end{array}$ & Anais UEMS & $\begin{array}{l}\text { Suscitar reflexões acerca da } \\
\text { identidade e algumas especificidades } \\
\text { de ser professor/a iniciante por meio } \\
\text { de um diálogo com pesquisadores/as } \\
\text { que discutem na atualidade a } \\
\text { diversidade do referido tema, como } \\
\text { André (2012), Candau (2014), } \\
\text { Contreras (2002), Cunha e Veiga } \\
\text { (1997), Gómez (1998), Gama e } \\
\text { Terrazzan (2012), Imbernón (2004), } \\
\text { Pimenta (2002), Tardif (2002), Veiga } \\
\text { (2008), entre outros. }\end{array}$ & $\begin{array}{l}\text { A formação docente assume um papel que } \\
\text { transcende o ensino que permeia a mera } \\
\text { atualização científica, pedagógica e didática e } \\
\text { se transforma na possibilidade de criar laços } \\
\text { de participação, reflexão e formação para que } \\
\text { as pessoas possam de alguma forma, } \\
\text { aprenderem a se adaptarem à convivência das } \\
\text { mudanças e incertezas do mundo em que } \\
\text { vivemos, assim como relatado pela Professora } \\
\text { Iniciante entrevistada para compor este } \\
\text { cenário. }\end{array}$ \\
\hline
\end{tabular}

Continua

2018

Camargo, Cadernos da Pedagogia

professora: ser profissional da

Franciele Suckergo,

Franciele Sueke Martins
Biagini, Patricia dos

Santos Corrêa.

Verificar como os professores Foi possível apontar fragilidade no que diz compreendem/descrevem sua respeito a formação específica para formação para atuação com crianças. formação para atuação com crianças. compreensão da infância, da criança pequena e da educação infantil, podendo assim
destacar a relevância de sólida formação destacar a relevância de sólida formação
inicial para a atuação/prática pedagógica de professores da educação infantil.

2018 Formação de professores e construção da identidade profissional docente
Mateus de Souza Coelho Filho, Ghedin
Anais do IV COLBEDUCA Colóquio Luso-Brasileiro Educação
Analisar como a formação de rofessores ajuda a construir dentidade profissional docente.

578
O processo formativo pode possibilitar a construção da identidade profissional docente na medida que instrumentaliza os sujeitos com um conjunto de saberes, conhecimentos e experiências teóricas e práticas da tessitura na trajetória formativa. 
Revista Ibero- Americana de Humanidades, Ciências e Educação- REASE $\quad$ open ○ $^{\text {access }}$

\begin{tabular}{|c|c|c|c|c|c|c|}
\hline$\# \mathbf{N}$ & Data & Título & Autores & Periódico & Objetivos & Resultados \\
\hline 10 & 2018 & $\begin{array}{l}\text { Identidade, docência } \\
\text { formação de professoras que } \\
\text { atuam em creches: } \\
\text { diálogo com a pesquisa }\end{array}$ & $\begin{array}{l}\text { Núbia Schaper } \text { Santos, } \\
\text { Víviam Carvalho de } \\
\text { Araújo, Wagner Silveira } \\
\text { Rezende. }\end{array}$ & Colloquium Humanarum & $\begin{array}{l}\text { Construir o perfil das professoras que } \\
\text { atuam em } 26 \text { creches conveniadas do } \\
\text { município, buscando compreender } \\
\text { quais são os saberes/fazeres docentes } \\
\text { necessários para atuação com bebês e } \\
\text { crianças na faixa etária de } 0 \text { a } 3 \text { anos } \\
\text { de idade. }\end{array}$ & $\begin{array}{l}\text { O estudo aponta para a necessidade de uma } \\
\text { articulação orgânica entre as políticas de } \\
\text { Educação em nosso país, sendo fundamental } \\
\text { que o poder público municipal assuma, de } \\
\text { fato, as creches como primeira etapa da } \\
\text { Educação Básica. }\end{array}$ \\
\hline
\end{tabular}

Continua 
Revista Ibero- Americana de Humanidades, Ciências e Educação- REASE

\begin{tabular}{|c|c|c|c|c|c|c|}
\hline$\# \mathbf{N}$ & Data & Título & Autores & Periódico & Objetivos & Resultados \\
\hline 11 & 2018 & $\begin{array}{lr}\text { Singularidades } & \text { na } \\
\text { constituição } & \text { da } \\
\text { profissionalidade } & \text { de } \\
\text { professoras da } & \text { educação } \\
\text { infantil } & \end{array}$ & Mônica Martins Samia & Unisul & $\begin{array}{l}\text { Contribuir para maior delineamento } \\
\text { de elementos constitutivos da } \\
\text { profissionalidade de professoras da } \\
\text { Educação Infantil, considerando as } \\
\text { diferentes representações sobre sua } \\
\text { função social e na vida das crianças. }\end{array}$ & $\begin{array}{l}\text { Os estudos, orientações e análises de cenário } \\
\text { revelam que os problemas e dilemas da } \\
\text { Educação Infantil já foram bastante mapeados } \\
\text { e já há elementos empíricos e teóricos } \\
\text { suficientes, tanto para ter uma visão mais } \\
\text { consistente do que é uma Educação Infantil } \\
\text { de qualidade, quanto para a construção e o } \\
\text { fortalecimento da profissionalidade das } \\
\text { professoras. Na realidade brasileira, a } \\
\text { urgência é que se instaurem com mais } \\
\text { efetividade as mudanças necessárias na } \\
\text { formação universitária e contínua, de forma } \\
\text { que favoreçam a construção de um perfil } \\
\text { profissional singular, para a atuação junto às } \\
\text { crianças, ao tempo que sejam criadas } \\
\text { condições estruturais para que este } \\
\text { atendimento de qualidade possa ocorrer. }\end{array}$ \\
\hline 12 & 2018 & $\begin{array}{l}\text { Saberes e fazeres de uma } \\
\text { professora de bebês na } \\
\text { Educação Infantil }\end{array}$ & $\begin{array}{l}\text { Raiza Fernandes Bessa de } \\
\text { Oliveira. }\end{array}$ & $\begin{array}{l}\text { Dissertação apresentada ao } \\
\text { Programa de Pós-Graduação } \\
\text { em Ensino e Processos } \\
\text { Formativos, do Instituto de } \\
\text { Biociências, Letras e Ciências } \\
\text { Exatas da UNESP }\end{array}$ & $\begin{array}{l}\text { Colaborar na construção de uma } \\
\text { Pedagogia da Primeiríssima Infância, } \\
\text { ao passo em que esclarece a } \\
\text { profissionalidade e intencionalidade } \\
\text { educativas presentes na prática } \\
\text { docente de uma profissional que } \\
\text { trabalha com bebês. }\end{array}$ & $\begin{array}{l}\text { Os resultados indicam diversos saberes e } \\
\text { fazeres da docência com os bebês e as } \\
\text { crianças bem pequenas em ambientes de } \\
\text { eduçąão formal e coletiva, possibilitando a } \\
\text { discussão acerca dos obstáculos e desafios } \\
\text { deste trabalho, além de abordar diferentes } \\
\text { aspectos que dizem respeito ao atendimento } \\
\text { de qualidade na Educação Infantil. }\end{array}$ \\
\hline 13 & 2018 & $\begin{array}{l}\text { Conceito de identidades e a } \\
\text { identidade profissional } \\
\text { docente }\end{array}$ & $\begin{array}{l}\text { Alberto } \\
\text { Gomes }\end{array}$ & Colloquium Humanarum & $\begin{array}{l}\text { Abordar através de uma breve } \\
\text { revisão bibliográfica, o conceito de } \\
\text { identidade. } \\
580\end{array}$ & $\begin{array}{l}\text { pensar numa (re) construção da identidade } \\
\text { docente, ou seja, a reinvenção da profissão, } \\
\text { tanto as formas de controle sobre o trabalho } \\
\text { docente veiculadas pelas políticas de } \\
\text { padronização (controle do Estado) quanto as } \\
\text { práticas de contestação e resistência } \\
\text { desencadeadas por docentes (sindicatos e } \\
\text { associações docentes) precisam ser revistas } \\
\text { pelos sujeitos que constroem suas } \\
\text { identidades: os próprios professores. }\end{array}$ \\
\hline
\end{tabular}


Revista Ibero- Americana de Humanidades, Ciências e Educação- REASE ${ }_{\text {open }}^{\text {access }}$






\section{A construção da identidade docente como requisito para a profissionalidade dos professores de bebês na educação infantil}

O presente estudo teve por objetivo apresentar uma revisão de artigos, a fim de discutir como a construção da identidade dos professores de bebês, é um fator imprescindível para a profissionalização docente na educação infantil.

Sabendo que a Educação Infantil obteve muitos avanços e a criança passou a ser reconhecida como um sujeito histórico e de direitos, principalmente a partir da promulgação da lei $n^{\circ}$ 9.394/96 que reconhece o seu direito a educação, desde o zero ano de idade, em instituições educacionais com a finalidade de cuidar e educar de forma global e harmônica (BAHIA, MOCHIUTTI e TRINDADE, 2020).

Contudo, embora sejam visíveis as transformações na política pública para a Educação Infantil ainda não houve mudanças significativas na qualificação da prática pedagógica dos professores de bebês e crianças pequenas, sendo uma possível explicação para esse fato a ausência de uma formação docente adequada e específica para esse trabalho (BAHIA, MOCHIUTTI e TRINDADE, 2020).

Dessa forma, é fundamental a construção de uma identidade do professor de crianças pequenas, assim como, garantir a esse profissional o acesso a formações adequadas que o conduza ao conhecimento e a reflexão dos saberes necessários ao trabalho com bebês e crianças pequenas (NASCIMENTO E LIRA, 2018).

Assim sendo, de acordo com Silva, Souza e Braga (2020) a construção da identidade profissional é influenciada pelo entrelaçamento do aspecto individual que corresponde a identidade de si e o aspecto coletivo que diz respeito a identidade para o outro e é desenvolvida por meio das relações externas em seus múltiplos contextos.

Desse modo, Gomes (2018) complementa ao dizer que a identidade possui simultaneamente uma dimensão individual a partir das ideias, concepções e representações construídas sobre si mesmo e uma dimensão coletiva que é fruto dos papéis sociais que os sujeitos desempenham em cada grupo social que pertence, como: familiar, profissional, escolar, religioso, etc.

Nessa visão, Nóvoa (1992) e Tardif (2002) defendem que a identidade docente diz respeito a um processo que ocorre ao longo da carreira e da trajetória de vida do sujeito (ONOFRE, TOMAZZETTI E MARTINS, 2017). E, também Pimenta (1999) defende que a identidade não é algo fixo e imutável nem muito menos algo externo que possa ser adquirido, mas sim um processo de construção do indivíduo situado num contexto sócio-histórico (JESUS E MELO, 2019).

Logo, a identidade dos professores é construída a partir de várias fontes de saberes e marcas de natureza pessoal e profissional caracterizando um arranjo complexo de histórias e conhecimento (SILVA, SOUZA E BRAGA, 2020).

Nesse segmento, Moreira et. al. (2020) corrobora ao afirmar que a identidade profissional é construída por meio de educação formal, da teoria que sustenta a prática, da 
relação estabelecida com outros professores e com as crianças, pelo discurso e na atuação profissional.

Assim embora, o campo de pesquisas sobre as identidades docentes seja recente há diversas pesquisas na área que compartilham da ideia de que as identidades docentes não são construções fixas e imutáveis, mas sim formas reflexivas que sinalizam muitas possibilidades de análise (OLIVEIRA e VIVIANI, 2019).

Posto isso, é possível afirmar que a identidade docente e o desenvolvimento profissional se dão por meio da transformação ecológica em que o docente se desenvolve e reconstrói durante toda a vida e em diferentes situações que abrangem o crescer, o sentir, o ser e o agir (OLIVEIRA - FORMOSINHO, 2011).

Desse modo, o tornar-se professor está estritamente ligado a história de vida do sujeito, sua visão da realidade, suas crenças e valores. E, num país como o Brasil em que a educação e a profissão professor é extremamente desvalorizada o ser professor vai além do fator econômico que não é nem um pouco atrativo, mas consiste em enxergar a educação como único caminho possível de mudar a realidade (JESUS E MELO, 2020).

Nesse sentido, segundo Stoll (2017) vivemos em uma sociedade com muitas referências de conteúdos e métodos de educação influenciando a forma como as escolas e os professores são vistos. E, o marco histórico e conceitual a respeito do trabalho na educação infantil tem influenciado a pratica pedagógica dos docentes, bem como, a construção da sua identidade pessoal e coletiva.

Assim sendo, para Cerisara (2002) a história da instituição da Educação Infantil é marcada por contradições e ambiguidades no que se refere ao processo de profissionalização dos docentes da educação infantil, uma vez que de um lado a proposta assistencialista esteve muito presentes na organização das primeiras creches e instituições voltadas a infância com o objetivo de guarda, proteção e alimentação destinado às crianças mais pobres e de outro lado um modelo de atendimento de educação pré-escolar de caráter preparatório para a próxima etapa da educação básica (Stoll, 2017).

Em consequência disso, a constituição da docência no âmbito da educação infantil pressupõe considerar o papel das relações de gênero e suas implicações na construção da identidade docente e suas determinações no que toca a feminização e contradições resultantes (BATISTA e ROCHA, 2018).

Por isso, nota-se significativas mudanças e marcas históricas nas práticas e conquistas obtidas na educação infantil. Entretanto, ainda há uma busca significativa pela profissionalização do professor da educação infantil, rompendo com a maternagem, o feminino e o assistencialismo que deixou marcas profundas no atendimento das crianças nas creches (MOREIRA et al., 2020).

$\mathrm{Na}$ visão de Moreira et. al. (2020) tais situações sem dúvida possibilitam as discrepâncias necessárias para a compreensão do profissional atual, um sujeito que enfrenta muitos desafios, que já conquistou direitos e que têm muitos desafios a serem enfrentados e muito ainda o que conquistar. 
Assim, para a superação das contradições que envolvem a valorização do professor e da escola, bem como, o enfrentamento dos inúmeros desafios que se colocam diante do contexto educativo se faz necessário que os docentes desenvolvam a sua profissionalidade (FILHO e GHEDIN, 2018).

Diante disso, compreende-se que somente a formação inicial oferecidas aos professores de educação infantil não é suficiente para oportunizar o aprendizado dos saberes necessários a esse trabalho docente que difere das demais etapas de ensino por possuir algumas peculiaridades como o binômio educar e cuidar de bebês e crianças pequenas num ambiente coletivo (BAHIA, MOCHIUTTI e TRINDADE, 2020).

Nessa perspectiva, o professor de educação infantil é um professor singular, pois trabalhar com crianças pequenas e por isso deve considerar as especificidades delas consequentemente se faz necessário que tenha uma formação focada nessas especificidades considerando o "educar" e o "cuidar" como dois pontos essenciais do trabalho na educação infantil (CAMARGO, BIAGINI e CORRÊA, 2018).

Logo, segundo Rocha (2012) a formação do docente necessita ter uma intencionalidade possibilitando ao professor a sua própria performance como profissional (CAMARGO, BIAGINI e CORRÊA, 2018). E, a formação para a docência tem como marca a busca ininterrupta diante aos desafios e está ligada a um rol de situações e apoios necessários constituintes do específico do ser professor, não dependendo unicamente do seu desejo nem muito menos limitando-se ao individualismo, mas possibilitando o caminhar ao longo da carreira (CARVALHO, 2018).

Com isso, para Carvalho (2018), segundo Candau (2014) ser professor hoje, é enxergar uma transformação na sua ação desafiando sua resistência, saúde e equilíbrio emocional, capacidade de resiliência e construção diária de experiencia pedagógicas significativas, ou seja, é fundamental não desvincular do processo de formação profissional tanto do contexto sociocultural quanto dos problemas que a escola enfrenta na atualidade, pois tais transformações afeta diretamente sua identidade profissional e servindo também de uma possibilidade de crescimento pessoal e profissional.

Diante disso, vale ressaltar que segundo Silva et al. (2018) o perfil de professor de bebês necessário nos centros de educação infantil ainda precisa ser inventado e esse professor precisará compreender profundamente os processos de desenvolvimento infantil para assim construir o seu modelo de prática pedagógica.

Além disso, o trabalho com bebês e crianças bem pequenas pouco aparece na formação inicial dos professores de bebês, o que consequentemente conduz a muitos desafios na construção de saberes e práticas para o trabalho docente com crianças dessa faixa etária. Assim sendo, segundo Oliveira (2018, p. 142):

... a falta de uma formação profissional consistente... e a inexistência de discussões a respeito de um currículo para os bebês nos cursos de formação inicial dos professores, faz com que os saberes e práticas sejam pouco teorizados e acabem constituindo-se a partir do senso comum. 
E, várias pesquisas a respeito da formação continuada e da profissionalização docente apontam para a importância de repensar-se a prática pedagógica, assim como, a necessidade do constante aprimoramento docente a partir do âmbito escolar como espaço de formação de professores empenhados num trabalho em equipe, na reflexão conjunta e no estudo coletivo (BEMFICA, TEIXEIRA e AMORIM, 2017).

Nessa perspectiva, de acordo com Nóvoa (2019) se faz necessário ressignificar os saberes teóricos e científicos no espaço da profissão uma vez que é na complexidade de uma formação ampliada a partir das experiencias e das culturas profissionais que é possível solucionar os desafios e dilemas dos docentes.

A esse respeito, Oliveira (2018) complementa ao afirmar que existem pesquisas que evidenciam que ainda são poucas as discussões e disciplinas referentes à educação das crianças de 0 a 3 anos nos currículos dos cursos de formação inicial para docentes da Educação básica.

Em vista disso, a necessidade de instigar uma mudança nos currículos atuais dos cursos de Pedagogia que por ofertar um leque muito amplo de possibilidades de atuação dedica pouco espaço para a formação do profissional que atuará com bebês e crianças pequenas, bem como, a urgência de estreitamento das relações entre as instituições formadoras e os centros de educação infantil (VASQUES e SARTI, 2017).

Dessa maneira, segundo Santos, Araújo e Rezende (2018) a formação dos professores de crianças pequenas deve contemplar não somente os saberes produzidos e sistematizados pela academia, mas também a partir do permanente diálogo com outros espaços, como o contexto das práticas no cotidiano da educação infantil.

Além disso, a formação continuada deve ocorrer no espaço escolar visto que é o lugar em que ela se define, enriquece-se e cumpre o seu papel no desenvolvimento profissional dos professores (NÓVOA, 2019).

Nessa visão, para Samia (2018) já temos muitos estudos que revelam os problemas e os dilemas da Educação infantil e eles já são suficientes para mostrar de modo mais consistente o que é a educação infantil de qualidade e a importância da profissionalidade docentes.

E consequência disso, o desafio urgente que se impõe no momento atual são as transformações necessárias na formação inicial e continuada, a fim de favorecer a construção de um perfil de professore singular para a atuação e o atendimento de qualidade junto às crianças da educação infantil (SAMIA, 2018).

Contudo, é essencial que ao falar sobre a educação infantil, comecem a falar sobre os bebês e os professores de bebês, a fim de divulgar a sociedade que na categoria professores existem os professores de bebês. E, enxergar, ter interesse pelos bebês e pelos professores estando atendo o que acontece na educação infantil diz respeito a um compromisso éticopolítico que cada pessoa deve assumir nessa sociedade que ainda discrimina grupos humanos, profissionais e profissões (SANTOS, 2020).

E, de acordo com Santos (2020) embora os professores da educação infantil estão sob o mesmo ordenamento dos demais professores da educação básica legal e políticas públicas 
educacionais e muitas vezes trabalham na mesma escola, porém são vistos com olhos diferentes um dos outros, isto é, na esfera pública da perspectiva do salário base, há uma equivalência salarial entre os professores das três etapas da Educação Básica, a partir da implementação da lei $\mathrm{n}^{\circ}$ 11.738/08 referente ao Piso Salarial Profissional Nacional, porém do ponto de vista social e político, os professores da educação infantil são vistos de formas diferentes e essas diferenças são expressas dentro e fora da escola tanto de modo implícito quanto explícito.

Além do mais, em relação aos professores tais diferenças são ainda mais acentuadas e explícitas. E, tal fato demonstra uma visão preconceituosa sobre a ação pedagógica com os bebês, ou seja, além de suas atividades docentes o professor ainda necessita convencer os outros de que trabalham e não passam o dia sem fazer nada (SANTOS, 2020), ou seja, que o trabalho no berçário possui intencionalidade, sistematização e comprometimento com o desenvolvimento global dessas crianças.

Sabe-se que a visão assistencialista da educação de bebês que foi historicamente construída contribui muito para a desvalorização do trabalho e dos profissionais que trabalham com crianças dessa faixa etária e consequentemente dificulta a consolidação das ações pedagógicas e da profissionalidade educativa existente nesse ambiente (OLIVEIRA, 2018).

Todavia, vale ressaltar que tanto as instituições de educação infantil quanto os seus profissionais tem feito um grande esforço para a promoção de atendimento de qualidade às crianças, porém é necessário ir na contramão dos discursos que dificultam o processo de (re)construção do atendimento das crianças pequenas no âmbito da educação infantil (OLIVEIRA, 2018).

Portanto, é de suma importância a importância a construção da identidade dos professores de bebês, uma vez que pode ser o instrumento que conduzirá os docentes ao desenvolvimento da sua profissionalidade e consequentemente o reconhecimento e a valorização do seu trabalho docente.

\section{Concluindo e finalizando}

No decorrer do presente estudo que esteve voltado em apresentar uma revisão de artigos, a fim de discutir como a construção da identidade dos professores de bebês é um fator imprescindível para a profissionalização docente na educação infantil, foi possível verificar que a construção da identidade do professor de bebê é fundamental para que esse profissional tenha o seu trabalho pedagógico reconhecido e valorizado e com isso ocorra a superação da visão assistencialista do atendimento de bebês na educação infantil.

Desse modo, a escola no cenário atual vem enfrentando muito problemas e desafios o que exige do profissional docente uma capacidade muito grande de resiliência e resistência o que consequentemente influencia a sua identidade profissional podendo também servir como um meio de crescimento pessoal e profissional.

Diante disso, a garantia do acesso do professor do berçário a cursos de formação continuada de longa duração e de qualidade capazes de contribuírem com o desenvolvimento 
dos saberes específicos e necessários ao trabalho com bebês é de extrema importância, pois possibilita a criação de um novo perfil profissional, a construção da sua identidade, a ressignificação da prática e por conseguinte a profissionalidade docente.

Assim sendo, se faz necessário uma mudança nos currículos dos cursos de formação inicial com o intuito de abrir mais espaço para a formação do profissional que atuará com bebês, bem como, que ocorra uma aproximação entre as instituições formadoras e os centros de educação infantil.

Além disso, a divulgação massiva sobre a importância da educação infantil adequada é fundamental, uma vez que contribui com a superação do caráter assistencialista que durante muito tempo lhe foi atribuída. E, nessa divulgação é imprescindível que em tal divulgação seja dado ênfase aos bebês, ao trabalho que é realizado com eles nesse espaço coletivo e aos professores de bebês, a fim de que a sociedade compreenda e reconheça a existência dos professores de bebê e que a partir disso ocorra a valorização profissional desses docentes.

Portanto, no que diz respeito ao universo da educação infantil, em especial os bebês e professores de bebês, é fulcral que todos da sociedade passem a olhar esse universo de modo mais vagaroso e sensível tentando enxergar assim as sutilizas e peculiaridades dos bebês e crianças pequenas nessa etapa de ensino da educação básica.

\section{REFERÊNCIAS}

BAUMAN, Zigmunt. Modernidade líquida. 1 ed. Rio de Janeiro: Zahar, 2001. 275p.

BAHIA, Celi da Costa Silva. MOCHIUTTI, Solange. TRINDADE, Marileia Pereira. Formação e prática de professores de bebês: entrelaços com os cursos de docência na educação infantil na universidade federal do Pará. 2020. Disponível em: < https://www.brazilianjournals.com/index.php/BRJD/article/view/17464 > Acesso em: 06 de fev. de 2021.

CAMARGO, Daiana. BIAGINI, Franciele Sueke Martins. CORRÊA, Patricia dos Santos. De cuidadora a tia, de tia a professora: ser profissional da educação infantil. 2018. Disponível em: < https://publicacoes.ifc.edu.br/index.php/MEPEC/article/view/226> Acesso em: 06 de fev. de 2021.

CARVALHO, Janaina Nogueira Maia. Ser professor/a iniciante reflexões sobre sua identidade e especificidades. 2018. Disponível em: < https://anaisonline.uems.br/index.php/seminarioformacaodocente/search/search?simpleQuery $=$ Ser + professor $\% 2 \mathrm{Fa}+$ iniciante + reflex $\% \mathrm{C} 3 \% \mathrm{~B} 5 \mathrm{es}+$ sobre+sua+identidade+e+especificidades \&searchField=title > Acesso em: 06 de fev. de 2021.

FERREIRA, Aurélio Buarque de Holanda. Mini Aurélio: o dicionário de língua portuguesa. 8 ed. rev. atual. Curitiba: Positivo, 2010.

FILHO, Mateus de Souza Coelho. GHEDIN, Evandro Luiz. Formação de professores e construção da identidade profissional docente. 2018. Disponível em: <https://www.revistas.udesc.br/index.php/colbeduca/article/view/11502> Acesso em: 06 de fev. de 2021. 
GOMES, Alberto Albuquerque. Conceito de identidades e a identidade profissional docente. 2018. Disponível em: < https://revistas.unoeste.br/index.php/ch/article/view/2481> Acesso em: 06 de fev. de 2021.

JESUS, Claudiane Pinto Dias de. MELO, Maria Alice. Profissão Professor: considerações sobre a identidade docente. 2019. Disponível em: < https://www.editorarealize.com.br/artigo/visualizar/62224> Acesso em: 06 de fev. de 2021.

MOREIRA, Alessandro Messias. GOMES, Celso Augusto dos Santos. SILVA, Renan Antônio da. GAZOLLA, Stefano Barra. OLIVEIRA, Felipe Flausino de. GUEDES, Luiz Carlos Vieira. Ser e se sentir professor na educação infantil: o que falam os docentes. 2020. Disponível em:

https://revista.unitins.br/index.php/humanidadeseinovacao/article/view/2680\#: :text=A\%20E duca $\%$ C3\%A7\%C3\%A3o\%20Infantil\%20\%E2\%80\%93\%20EI\%20avan\%C3\%A7ou,sua\%20 pr\%C3\%A1tica\%20no\%20saber\%20cient\%C3\%ADfico.> Acesso em: 06 de fev. de 2021.

NASCIMENTO, Edaniele Cristine Machado do. LIRA, Aliandra Cristina Mesomo. Docência com crianças de 0 a 3 anos e as ações de cuidado e brincadeiras. 2018. Disponível em: < https://revista.fct.unesp.br/index.php/Nuances/article/view/4567> Acesso: 15/06/2020 às 9 h $20 \mathrm{~min}$.

NÓVOA, António. Os Professores e a sua Formação num Tempo de Metamorfose da Escola. 2019 Disponível em: <https://www.scielo.br/scielo.php?script=sci_arttext\&pid=S2175-62362019000300402>

Acesso em: 18 de jan. de 2020.

OLIVEIRA - FORMOSINHO, Júlia. O desenvolvimento profissional das educadoras de infância: entre os saberes e os afetos, entre a sala e o mundo. In. MACHADO, Maria Lucia A. Encontros e Desencontros na Educação Infantil. 3. ed. São Paulo: Cortez: Autores Associados, 2011, p.133-167.

OLIVEIRA, Raiza Fernandes Bessa de. Saberes e fazeres de uma professora de bebês na Educação Infantil. 2018. Disponível em: https://repositorio.unesp.br/handle/11449/154927> Acesso em: 06 de fev. de 2021.

OLIVEIRA, Rosmari Pereira de. VIVIANI, Luciana Maria. Entre a fralda e a lousa: A questão das identidades docentes em berçários. 2019. Disponível em: <https://revistas.rcaap.pt/rpe/article/view/14947 > Acesso em: 06 de fev. de 2021.

ONOFREI, Márcia Regina. TOMAZZETTI, Cleonice Maria. MARTINS, Andressa. Processos formativos de professoras de Educação Infantil: olhares sobre a profissão. 2017. Disponível em:

https://periodicoscientificos.ufmt.br/ojs/index.php/educacaopublica/article/view/2470 Acesso em: 06 de fev. de 2021.

SAITO, Heloísa Toshie Irie. OLIVEIRA, Marta Regina Furlan de. Trabalho docente na Educação Infantil: Olhares reflexivos para a ação intencional e planejada do ensino. 2018. Disponível em: <http://periodicos.uem.br/ojs/index.php/ImagensEduc/article/view/39310> Acesso: 15/06/2020 às 9 h 25 min. 
SAMIA, Mônica Martins. Singularidades na constituição da profissionalidade de professoras da educação infantil. 2018. Disponível em: < http://www.portaldeperiodicos.unisul.br/index.php/Poiesis/article/view/5901> Acesso em: 06 de fev. de 2021.

SANTOS. Marlene Oliveira dos. A solidão profissional de professoras de bebês. 2020. Disponível em: <https://www.e-publicacoes.uerj.br/index.php/riae/article/view/46690 > Acesso em: 06 de fev. de 2021.

SANTOS, Núbia Schaper. ARAÚJO, Víviam Carvalho de. REZENDE, Wagner Silveira. Identidade, docência e formação de professoras que atuam em creches: um diálogo com a pesquisa. 2018. Disponível em: < http://journal.unoeste.br/index.php/ch/article/view/2451 > Acesso em: 06 de fev. de 2021.

SILVA, Jéssica Francine Ferreira da. SOUZA, Ana Paula Gestoso de. BRAGA, Andréia Barboza.

Reflexões sobre a construção da identidade profissional de uma docente da educação infantil. 2020. Disponível em: <http://www.ufopa.edu.br/portaldeperiodicos/index.php/revistaexitus/article/view/886> Acesso em: 06 de fev. de 2021.

SILVA, José Ricardo et al. (Org.). Educação de bebês: cuidar e educar para o desenvolvimento humano. 2 ed. São Carlos: Pedro \& João Editores, 2018. 308 p.

STOLL, Ana Paula Nunes. A constituição das identidades das educadoras que trabalham na educação infantil e sua relação com os saberes docentes. 2017. Disponível em: < http://svr-net20.unilasalle.edu.br/handle/11690/751> Acesso em: 06 de fev. de 2021.

VASQUES, Andréia Lopes Pacheco. SARTI, Flavia Medeiros. O Entre o 'aproveitamento' e o provimento da prática na formação continuada de professores. 2017. Disponível em: < http://periodicos.uem.br/ojs/index.php/ActaSciEduc/article/view/28595> Acesso em 25 de jun. de 2020 . 